\title{
A Model to Identify the Dimensions of Mobile Service Quality
}

\author{
Emmanouil Stiakakis \\ Department of Applied Informatics \\ University of Macedonia \\ Thessaloniki, Greece \\ stiakakis@uom.gr
}

\author{
Christos K. Georgiadis \\ Department of Applied Informatics \\ University of Macedonia \\ Thessaloniki, Greece \\ geor@uom.gr
}

\begin{abstract}
The aim of this paper is to identify the dimensions of mobile service (m-service) quality. Based on the literature review and intervening to specific theoretical frameworks according to some critical characteristics of the mobile setting (security, personalization, etc.), a new hierarchical and multidimensional model is proposed. This model is validated using confirmatory principal component analysis of the data collected through an empirical research conducted among m-service users. The eleven components, which were extracted, are consistent with the dimensions suggested in our model.
\end{abstract}

Keywords: mobile service; service quality; mobile Internet

\section{INTRODUCTION}

Mobile Internet, defined as the wireless access to Internet content via mobile devices, promises to users access to tremendous amount of information and products available on the Internet, anywhere and anytime [1]. Quality of Service (QoS) is now seen as one of the most critical components for the organization's success. The confirmed relationship of QoS with business performance, lower costs, customer satisfaction, customer loyalty, and profitability has further motivated both the researchers and practitioners to explore this concept [2].

Delivering high quality service is considered a crucial strategy for business success and survival [3]. In the beginning, the main emphasis of both managerial and academic attempts focused on developing strategies to meet customer expectations and understand e-service quality in terms of Web interactivity (e.g., [4]). Such approaches on measuring e-service quality using indications that emerge from interacting with the website were found to be insufficient to measure the quality of the online service experience [5]. There is a need to go beyond the website interface in defining quality: a customer's online buying experience consists of everything from information search, product evaluation, decision making, carrying out the transaction, delivery, returns, and customer service [6]. In this setting of e-service experience, e-service quality is defined as the extent to which a website facilitates efficient and effective shopping, purchasing, and delivery of products and services [7]. Voss particularly, in his sequence dependent approach [8], claims that above and beyond the base-level foundation of service, the next level of capabilities that create customer centered service and add value to the customer should be that which creates advantage in the market place. Therefore, measuring the quality of the eservice experience includes cues that happen before, during, and after the e-purchase transaction.

In addition, many of the research projects studying the design of the website interface include all kinds of sites. This approach may negate recognition of situation specific issues (e.g., consumers have different motivations for interacting with news and entertainment websites than they do for shopping online) [6]. The tendency to conceptualize e-service delivery as a single, uniform activity may cause insights being drawn from, and applied to, incompatible circumstances [9].

In order to deliver superior service quality, managers should firstly understand how customers perceive and evaluate the customer service. To that end, many researchers did many studies in order to present models. These models consist of dimensions which assess the service quality delivered to mobile phones' users. In the context of this, the primary aim of our work is to develop and validate a model for identifying the main components of mobile service (m-service) quality. In this regard, this paper makes an attempt to study the various QoS parameters and explore the way by which they can be mapped. Furthermore, it validates the suggested model through a survey conducted among users of mobile services.

This paper is organized as follows: in Section II, the need for this study is highlighted and a generalized set of pertinent factors to this study is discussed. Section III presents the suggested model to assess m-service quality, identifying its main components. Section IV explains how the suggested model was validated through a survey, while the findings of that survey are given in Section V. Finally, the conclusions are summarized in Section VI.

\section{LITERATURE REVIEW- CONCEPTUAL BACKGROUND}

The literature shows no consensus on the extent and type of dimensions that reflect the ideals of electronic/mobile service quality, not even those of service quality in general $[10 ; 11 ; 12 ; 13]$. However, it is useful to mention the most popular models used to define the quality of services. 


\section{A. Service Quality}

According to the Nordic model [14], a pioneer work in the area of quality of services, the quality in traditional people-oriented services is estimated from the comparison between the expected and perceived quality. The model conceptualizes perceived service quality by differentiating between the 'what' (what the consumer receives as a result of his interaction with a service provider - technical quality) and 'how' (how they get the outcome resulting from their interactions with the seller - functional quality) components of the buyer-seller interaction (Fig. 1).

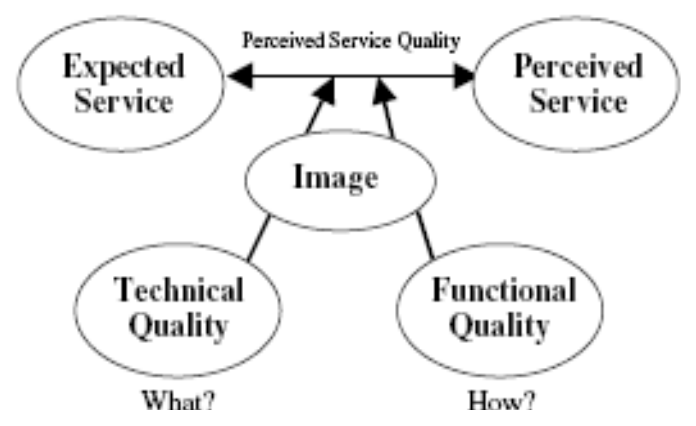

Figure 1: The Nordic Model

Brady and Cronin in [15] combined practice and theory together and justified the importance of developing favorable service among consumers. They developed a hierarchical multidimensional model, adopting at the first level the approach of Rust and Oliver [16], in which the overall quality is composed of three main dimensions: interaction (service delivery), outcome (service product), and physical environment (service environment). As it is depicted in Fig. 2, comparing to the Nordic model, the dimension of environment has been added. For each dimension, the following three sub-dimensions have been suggested:

\section{- Interaction quality}

- Attitude: friendly service

- Behavior: polite gestures

- Expertise: trained personnel

- Physical environment quality

- Ambient conditions: e.g., temperature

- Design: aesthetically attractive spaces

- Social factors: behavior of bystanders

- Outcome quality

- Waiting time: accuracy of service (in time)

- Tangibles: the obtained material goods

- Valence: the final impression.

\section{B. Quality of Electronic Services}

The quality of electronic services (e-services) is defined as the measure according to which an online service is able to meet customer needs efficiently and effectively [17].

Among the studies in the e-services area, the eSERVQUAL model [7] is noteworthy. Zeithaml et al. developed this model as a specialization on e-services of the SERVQUAL model [18], a widely used measurement scale for service quality. They analyzed why most online companies fail to respond effectively to their customers' requirements. The result of their analysis depicts the reasons for failure as internal business weaknesses and shortages [19]. The authors identified 11 e-service quality dimensions:

- Access (to the website or the company when needed).

- Assurance/trust (customer feels confident dealing with the site).

- Ease of navigation (moving easily and quickly through the website pages).

- Efficiency (site is simple to use, minimal data required as input by the customer).

- Flexibility (in accomplishing an electronic transaction).

- Customization/personalization (based on customer's preferences and purchase histories).

- Price knowledge (concerning total, shipping, and comparative prices).

- Security/privacy (site is safe from intrusion, personal information is protected).

- Site aesthetics (appearance attributes).

- Reliability (correct technical functioning of the site, keeping promises made to the customer).

- Responsiveness (quick response to customer's requirements).

Other models worthy of note in this category are the eS-QUAL and the e-RecS-QUAL scales suggested by Parasuraman et al. in [20]. The authors decreased the number of quality dimensions to seven:

- Efficiency (accessing and using the site easily and quickly).

- Fulfilment (keeping promises about order delivery and item availability).

- System availability (correct technical functioning of the site).

- Privacy (the site is safe, customer information is protected).

- Responsiveness (effective handling of problems).

- Compensation (the site compensates customers for problems).

- Contact (assistance through telephone or online representatives).

The first four dimensions were said to constitute "core" quality (e-S-QUAL scale), whereas the last three were said to constitute "recovery" quality (e-RecS-QUAL scale).

\section{Mobile Service Quality}

Mobile setting has several particularities that influence service quality. There is, at least, a need for a proper interpretation of the quality dimensions identified in the electronic context.

Chae et al. in [1] investigated m-service information quality considering information quality issues, as well as $\mathrm{m}$-commerce characteristics, such as context and mobile devices. They concluded on the following main factors of information quality for wireless Internet services: 


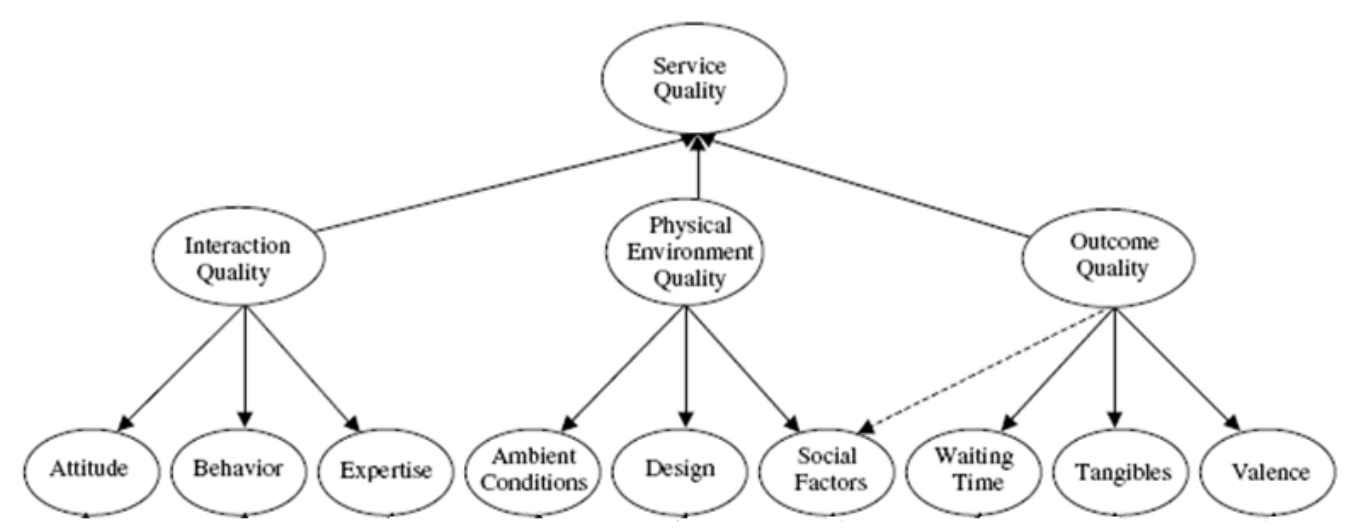

Figure 2: Model of Cronin and Brady

- Connection quality: dealing with consumers having access to stable m-services without interruption of connection. It also supports speedy system responses to users' requests.

- Content quality: referring to the inherent value and usefulness of the information provided by $\mathrm{m}$ services.

- Interaction quality: dealing mainly with the provision of easy and efficient $\mathrm{m}$-services.

- Contextual quality: referring to the ubiquitous nature of $\mathrm{m}$-services and personalization issues.

However, these four dimensions only focus on the information quality rather than service quality. As we have already mentioned, researchers in service quality area [16] examine additionally the environment as a critical factor which influences service quality. Moreover, according to e-service quality research [6;20], significant additional aspects are customer service and privacy/security.

In a relative recent work [21], the authors analyzed carefully the above literature in order to proceed with their research. They investigated the theoretical and empirical meaningfulness of a composite model of behavioral intentions in a pure mobile Internet services context. They finally suggested the dimensions of connection quality, content quality, interaction quality, contextual quality, customer service, privacy, and device quality.

In another study [22], Kar et al. adapted the quality dimensions of e-services (based on the SERVQUAL), to fit characteristics of $\mathrm{m}$-services. The five dimensions they identified include reliability, responsiveness, user interface, trust, and customization.

Much research on m-service quality has focused on the consumer behavior. Kim et al. in [23] initially identified six service quality measures, including call quality, pricing structure, mobile devices, value added services, convenience in procedures, and customer support. However, through an exploratory factor analysis, the dimensions of "mobile devices", "convenience in procedures", and "customer support" were eliminated. In the same way, Lim in [24] also identified five dimensions of consumers' perceived quality of m-services: pricing plans, network quality, data services, billing system, and customer service.

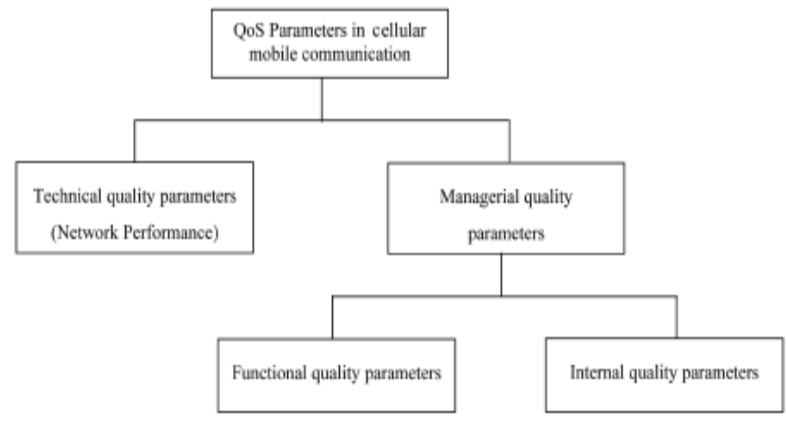

Figure 3: Classification of QoS Parameters in Cellular Mobile Communication

Seth et al. in [2] proposed that QoS in cellular mobile communication can be broadly categorized into technical and managerial parameters, as depicted in Fig. 3. Managerial parameters can be further categorized into functional and internal quality parameters. All the three categories are important for delivery of better QoS to customers, but authors underline that they are covered separately in the literature. Thus, the primary categorization of the QoS parameters is based on the segmentation in the literature pertaining to areas other than mobile communication:

- Technical parameters measure the network performance of cellular mobile communication network (e.g., call drop rate, network accessibility, etc.)

- Managerial parameters comprise functional, as well as internal quality parameters.

- Functional parameters measure how the service is delivered to the end customer [14].

- Internal quality parameters deal with the internal organizational dynamics. These parameters include top management commitment to quality, leadership, internal 


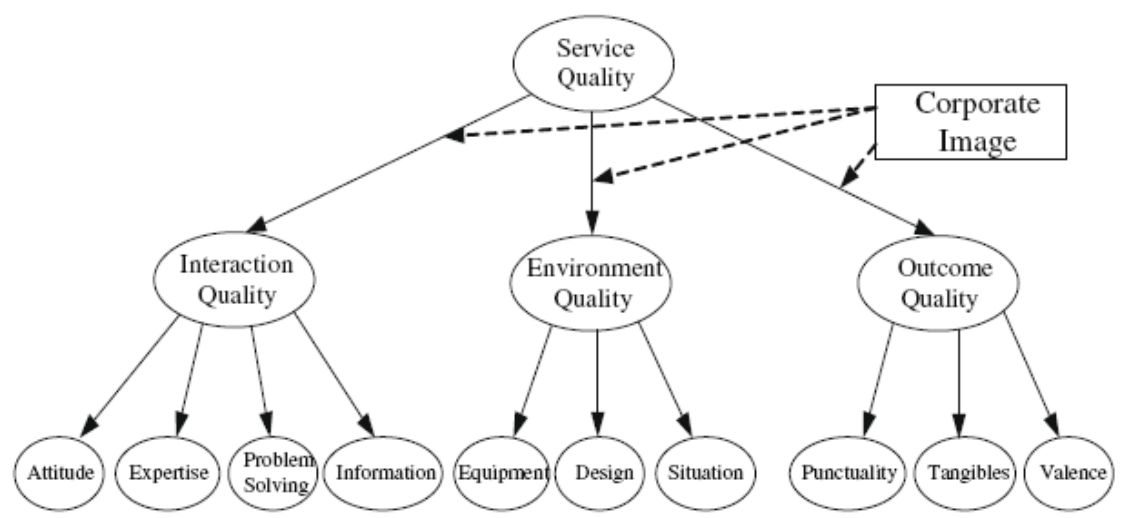

Figure 4: Mobile Brokerage Service Quality Model

departmental communication, employee empowerment, etc.

All of these parameters are either directly or indirectly related to customer satisfaction, profitability, and competitiveness in the market.

The same authors investigated service quality structure in [25] by combining both functional and technical quality attributes. Their study aimed at finding the relative importance of service quality dimensions from the customer's perspective. The proposed dimensions were: reliability, responsiveness, assurance, empathy, tangibles, convenience, and customer perceived network quality.

$\mathrm{Lu}$ et al. in [11] used data from the two largest mservice providers in China in order to show that corporate image moderates the effects of environment and outcome qualities on the service quality. Combining their findings from the qualitative research with the literature review for m-services, they summarized their multidimensional and hierarchical model of mobile brokerage service quality (Fig. 4) with the following dimensions:

- Interaction quality (attitude, expertise, problem solving, information).

- Environment quality (equipment, design, situation).

- Outcome quality (punctuality, tangibles, valence).

The three primary dimensions are consistent with the prior research $[15 ; 16]$. Each primary dimension has its own sub-dimensions. With the term "interaction quality" they mean the quality of customer's interaction with mservice provider during the service delivery. Also, in this work, "environment quality" means how the service is effectively transmitted from service providers to consumers. It is related, not only to providers, but consumers as well. The third dimension is "outcome quality", which is similar to technical quality proposed by Grönroos in [14]. The punctuality, tangibles, and valence influence the outcome quality.

Another significant approach is the recent study of Vlachos et al. [26], which theoretically is built upon the Nordic model of traditional service perceived quality, so as to investigate the e-service quality construct [15]. The 'what' component of Nordic model is addressed using the notions of aesthetics, whereas the 'how' component is addressed using the notions of ease of use and customer service among the others. The purpose of the study was to measure the perceived e-service quality for mobile Internet services.

The authors, studying the results of other researchers, such as $[15 ; 6 ; 27]$, concluded with the following familiar dimensions:

- Efficiency quality (ease of use, usefulness).

- Outcome quality (content variety, aesthetics).

- Customer care quality (customization, privacy, customer service).

\section{Noteworthy Points}

It is worth mentioning that Parasuraman et al. in [20] avoided including, in their model, parameters such as fun and entertainment since these parameters differ depending on the situation. In contrast, Fassnacht and Koese in [17] were critical to the research of Parasuraman et al. [20], and Wolfinbarger and Gilly [6] because the people who were asked were not interested in buying assets.

The concept of customer loyalty and its relation to quality dimensions is an important issue in the context of $\mathrm{e}-$ and $\mathrm{m}$-services. The quality-loyalty link was initially tested by aggregating quality dimensions $[13 ; 20]$. Recently, Swaid and Wigand, in a significant research effort [5], have investigated the impact of the dimensions of e-service quality on the different types of service loyalty.

As a final point, many researchers propose that service quality should be a hierarchical and multidimensional structure with sub-dimensions $[10 ; 11 ; 15 ; 21 ; 23 ; 25 ; 26 ; 28$; 29]. Specifically, Chen and Aritejo in [10] supported that this kind of model is the only method for correct and global assessment of m-service quality. In addition, Lu et al. in [11] stressed the restrictions and failures of others' models, suggesting that the multidimensional and hierarchical structure is the most appropriate method for assessing the m-service quality. Furthermore, Caro and Garcia in [29] alleged that their multidimensional model could overpass the restrictions of previous models (e.g., SERVQUAL and SERVPERF models). Finally, Vlachos et al. in [26] recognized that more and more researchers use these kinds of models. 


\section{SUGGESTED MOdel}

According to the aforementioned points, our suggested model is a hierarchical, multidimensional model, based primarily on the models of Brady and Cronin [15], and $\mathrm{Lu}$ et al. [11]. Its sub-dimensions are derived from the detailed and exhaustive study of the literature. The three core dimensions are: interaction quality, environment quality, and outcome quality (Fig. 5).

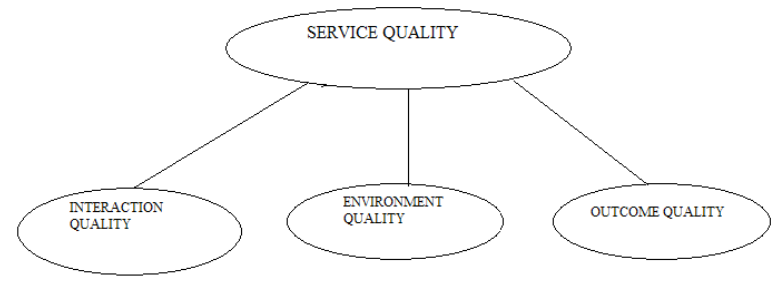

Figure 5: Core Dimensions of the Suggested Model

The core dimensions consist of the following subdimensions (Fig. 6):

- expertise, problem solving, information, security/privacy, and customization/personalization

- equipment, design, and context

- reliability, tangibles, and valence

The first dimension is interaction quality, which reflects the quality of a customer's interaction with $\mathrm{m}$ service provider during the service delivery. In our model, the interaction quality consists of the sub-dimensions of expertise, problem solving, information, security/privacy, and customization/personalization. $\mathrm{Lu}$ et al. in [11], and Caro and Garcia in [29] included expertise and problem solving as sub-dimensions of service quality. In the same path, Brady and Cronin in [15] supported that the expertise was a very important dimension ("providers should know all the details about their services").

In their studies, both Vlachos and Vrechopoulos [21], and Vlachos et al. [26] suggested that content, privacy, and customization are principal components of m-service quality. Besides, Chae et al. in [1] highlighted the importance of content, because consumers want up-todate, detailed, sufficient, and accurate market information. The assurance of the security of mobile services is also a principal quality dimension for all the consumers [30].

Moreover, during the service delivery process, the consumers usually provide their personal data online, so they demand privacy. Zeithmal et al. [27], Seith et al. [25], and Wolfinbarger and Gilly [6] also supported this view. Additionally, Chae et al. in [1], and Vlahos et al. in [26] pointed out that customization is part of interaction quality. The customers should feel that the service delivery is exclusively for them, meeting only their requirements. Success in developing conveniences into the mobile interface is based on understanding the particular user and their tasks, which is a matter of personalization [31].

The second dimension is environment quality. Many authors, such as $\mathrm{Lu}$ et al. in [11], Vlachos and
Vrechopoulos in [21], and Caro and Garcia in [29] considered that equipment is part of environment quality. The word "equipment" has two meanings. On the one hand, it refers to the wireless telecommunications network that the service provider uses. On the other hand, it refers to the mobile device that the consumer owns. It is evident in $[11 ; 15 ; 21]$ that the mobile device's design has a critical effect upon the service quality. It includes navigation, colour, shapes, font colour, and music. The last subdimension of environment quality is context, as also supported in $[11 ; 15 ; 16 ; 29]$.

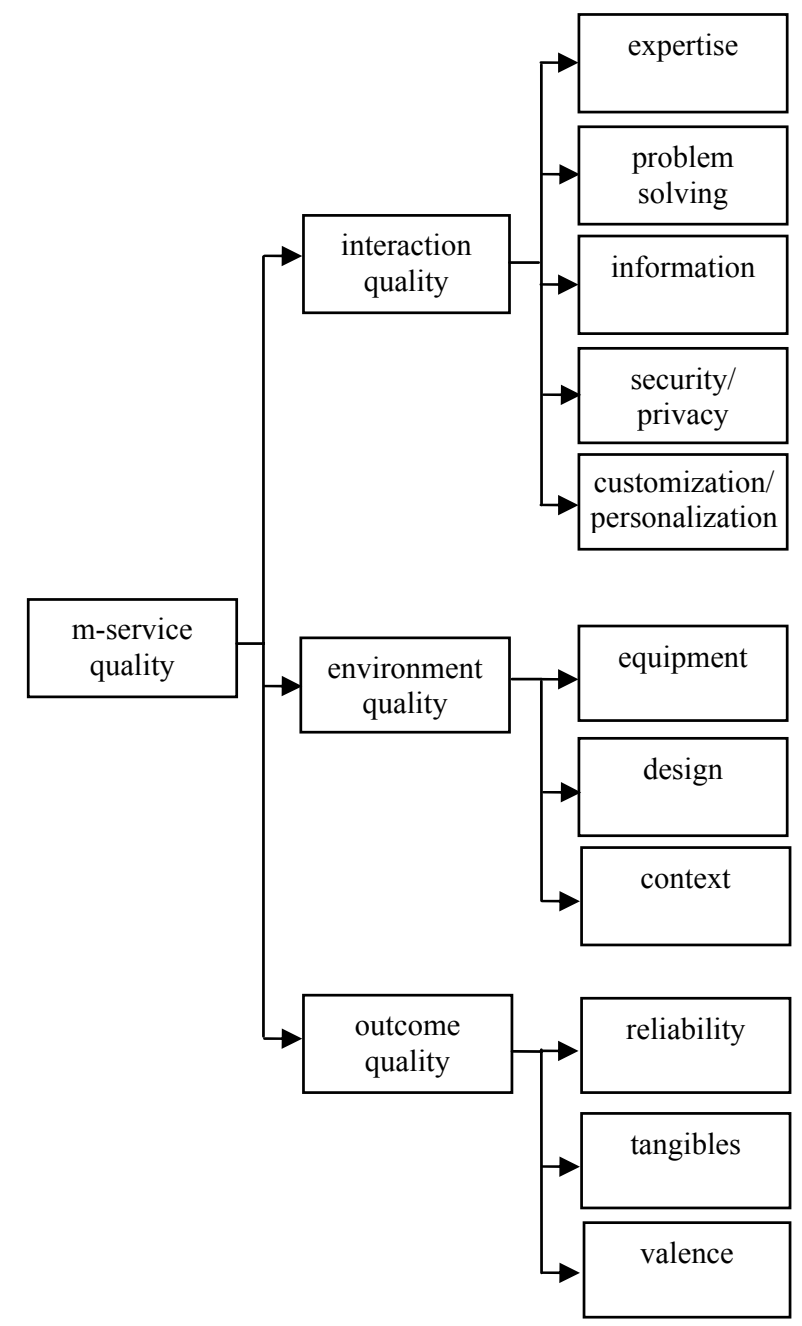

Figure 6: The Suggested Model

(Dimensions and Sub-dimensions)

The last dimension is outcome quality, which deals with the results of the service usage on the attitudes of people (psychologically and practically). It is quite similar to the technical quality proposed in [14]. From the literature review, it is obvious that a great part of surveys, which are relevant to quality of $\mathrm{m}$ - and e-services, focus mostly on how to deliver qualitative services and not on the results of this procedure. On the other hand, several researchers acknowledge the importance of examining all 
the aspects of the effects of the particular service on the customer attitude (the outcome dimension). Thus, our model recognizes three factors that influence the perceived outcome quality: reliability, tangibles, and valence.

The sub-dimension of reliability is the only feature of the outcome dimension which is included in most of the research studies. Indicatively, Chen and Aritejo in [10], Lu et al. in [11], and Seth et al. in [25] pointed out that consumers consider reliability as a very important part of their overall service quality perception. Following Brady and Cronin in [15], Lu et al. in [11], and Seth et al. in [25], our model also includes tangibles as an important factor that influences outcome quality.

Finally, the sub-dimension of valence is based on the work of Caro and Garcia in [29], Brady and Cronin in [15], and Lu et al. in [11]. Service quality has been shown to encourage customer loyalty and retention $[3 ; 20]$. Some researchers focused on e-service quality and its relation to attitude toward the website [6], intentions to return and reuse/purchase [13] and behavioural intentions [32]. The sub-dimension of the "final impression" presents a clear indication of the quality-preference loyalty relation in the m-service setting.

TABLE I. THE ANTECEDENTS OF THE SUB-DIMENSIONS

\begin{tabular}{|c|c|}
\hline $\begin{array}{l}\text { Sub- } \\
\text { dimensions }\end{array}$ & Research Work \\
\hline Expertise & $\begin{array}{l}\text { Brady and Cronin (2001); Caro and } \\
\text { Garcia (2007); Lu et al. (2009) }\end{array}$ \\
\hline Problem solving & $\begin{array}{l}\text { Caro and Garcia (2007); Lu et al. } \\
(2009)\end{array}$ \\
\hline Information & $\begin{array}{l}\text { Vlachos and Vrechopoulos (2008); } \\
\text { Vlachos et al. (2011); Chae et al. } \\
(2002)\end{array}$ \\
\hline Security/Privacy & $\begin{array}{l}\text { Zeithaml et al (2002); Vlachos and } \\
\text { Vrechopoulos (2008); Vlachos et } \\
\text { al. (2011), Seith et al. (2008); } \\
\text { Wolfinbarger and Gilly (2003) }\end{array}$ \\
\hline $\begin{array}{l}\text { Customisation/ } \\
\text { Personalization }\end{array}$ & $\begin{array}{l}\text { Vlachos and Vrechopoulos (2008); } \\
\text { Vlachos et al. (2011); Chae et al. } \\
(2002)\end{array}$ \\
\hline Equipment & $\begin{array}{l}\text { Lu et al. (2009); Vlachos and } \\
\text { Vrechopoulos (2008); Caro and } \\
\text { Garcia (2007) }\end{array}$ \\
\hline Design & $\begin{array}{l}\text { Lu et al. (2009); Vlachos et al. } \\
\text { (2011); Brady and Cronin (2001) }\end{array}$ \\
\hline Context & $\begin{array}{l}\text { Lu et al. (2009); Brady and Cronin } \\
\text { (2001); Rust and Oliver (1994); } \\
\text { Caro and Garcia (2007) }\end{array}$ \\
\hline Reliability & $\begin{array}{l}\text { Chen and Aritejo (2008); Lu et al. } \\
\text { (2009); Seth et al. (2008) }\end{array}$ \\
\hline Tangibles & $\begin{array}{l}\text { Brady and Cronin (2001); Lu et al. } \\
\text { (2009); Seth et al. (2008) }\end{array}$ \\
\hline Valence & $\begin{array}{l}\text { Caro and Garcia (2007); Brady and } \\
\text { Cronin (2001); Lu et al. (2009) }\end{array}$ \\
\hline
\end{tabular}

\section{RESEARCH}

In order to validate the theoretical framework, we tested whether the eleven sub-dimensions of the suggested model, i.e., expertise, problem solving, information, security/privacy, customization/personalization, equipment, design, context, reliability, tangibles, and valence constitute the main components of m-service quality. This was done through a survey conducted among m-service users. However, the direct evaluation of the aforementioned dimensions would not be an easy task, since m-service users could not rate the importance of terms, such as "valence" or "context". To address this issue, the eleven dimensions were firstly analyzed into 40 quality criteria (items); the analysis was accomplished by means of a number of experts. More specifically, six academics, whose the main research topic is about eservices and related technologies, were interviewed. Although the number of interviewees seems to be rather small, there was a consensus in their opinions regarding the quality criteria that comprise the eleven dimensions of m-service quality; thus, there was not any particular reason to increase the number of experts.

The forty quality criteria, in which the sub-dimensions of the suggested model were analyzed, were stated in the questionnaire used in the survey as simple and easy to understand sentences. Due to the large number of the criteria, only one criterion per sub-dimension is given in Table II (as stated in the questionnaire).

TABLE II. SUGGESTED CRITERIA OF M-SERVICE QUALITY

\begin{tabular}{|l|l|}
\hline $\begin{array}{l}\text { Sub- } \\
\text { dimensions }\end{array}$ & Quality Criteria \\
\hline Expertise & $\begin{array}{l}\text { M-service providers should be able } \\
\text { to answer your queries. }\end{array}$ \\
\hline Problem solving & $\begin{array}{l}\text { The prompt solution of any } \\
\text { problems related to the m-service } \\
\text { (by the provider) enhances your } \\
\text { satisfaction. }\end{array}$ \\
\hline Information & $\begin{array}{l}\text { M-service providers should give } \\
\text { precise information. }\end{array}$ \\
\hline Security/Privacy & $\begin{array}{l}\text { M-service providers can use your } \\
\text { personal data according to your } \\
\text { own discretion. }\end{array}$ \\
\hline $\begin{array}{l}\text { Customisation/ } \\
\text { Personalization }\end{array}$ & $\begin{array}{l}\text { An m-service should be adjusted } \\
\text { according to your profile. }\end{array}$ \\
\hline Equipment & $\begin{array}{l}\text { M-service providers should exploit } \\
\text { all the possibilities of advanced } \\
\text { mobile devices. }\end{array}$ \\
\hline Design & $\begin{array}{l}\text { The successive forms of an m- } \\
\text { service should carefully guide the } \\
\text { user. }\end{array}$ \\
\hline Context & $\begin{array}{l}\text { An m-service should exploit the } \\
\text { location information of the mobile } \\
\text { device. }\end{array}$ \\
\hline $\begin{array}{l}\text { M-service providers should } \\
\text { necessarily inform the user for }\end{array}$ \\
\hline
\end{tabular}




\begin{tabular}{|l|l|}
\hline & potential time delays. \\
\hline Tangibles & $\begin{array}{l}\text { M-service providers should provide } \\
\text { in-print evidence that the service or } \\
\text { a part of it has been accomplished. }\end{array}$ \\
\hline Valence & $\begin{array}{l}\text { An m-service, once it has been } \\
\text { completed, should create the feeling } \\
\text { of a good experience. }\end{array}$ \\
\hline
\end{tabular}

The respondents were asked to state the extent to which they agree or disagree with the aforementioned sentences; a Likert scale with five response categories, i.e., strongly agree, agree, neither agree nor disagree, disagree, and strongly disagree, was used in the questionnaire (of the survey), which also included questions about the usage of mobile devices (duration and frequency of use, types of service used, frequency of purchase/upgrading of a mobile device, etc.).

The sample used in our survey comprised 260 users of $\mathrm{m}$-services without any exception regarding the gender, age (over 15 years old), profession, and educational background. It should be noticed that the sample size was acceptable for factor analysis (the minimum sample size would have been 200 , i.e., five times the number of variables). The survey was conducted in two months period through personal interviews and electronic mail messages sent to potential respondents. Since there were no differences between the two sub-samples (according to our descriptive statistics), we used both methods of data collection to reach a satisfactory sample in a short period of time.

\section{FINDINGS}

Due to confined space of this paper, we present a very few descriptive characteristics of the sample used in the survey. In Fig. 7, the duration of use of a mobile device is depicted. As it can be seen, $53 \%$ of the respondents use a mobile device more than 10 years and $43 \%$ from 5 to 10 years. It is apparent that the participants in our sample were experienced users of mobile devices.

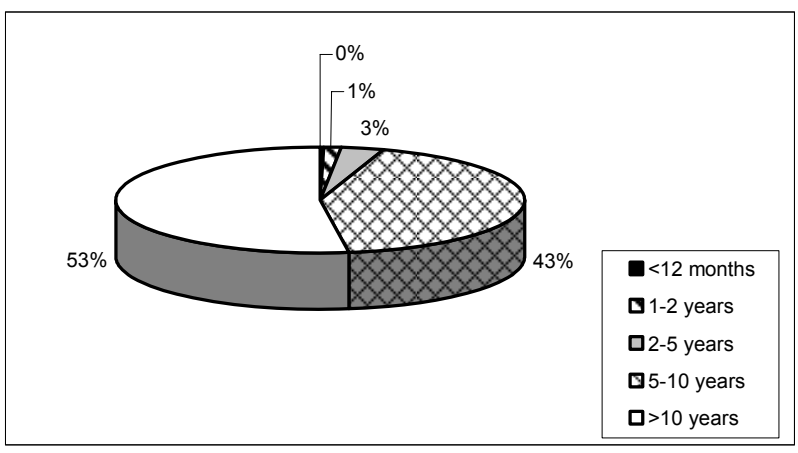

Figure 7: The sample used (duration of use of a mobile device)

Fig. 8 depicts how the respondents rated the importance of the preference criteria of a mobile device. The figure can help us to understand the reasons that motivate users to select a specific mobile device instead of another device. As we can see, the supplementary offerings (by the network provider) or the size / weight of the device are not good reasons to prefer a mobile device. The cost of purchasing a mobile device, the features of the device (e.g., Bluetooth, MP3 player, GPS), and its brand (in that order) are the most important preference criteria. It is expected that the access to the Internet, despite its low rating in our survey, to gain more importance in the near future due to the advances and variety of m-services.

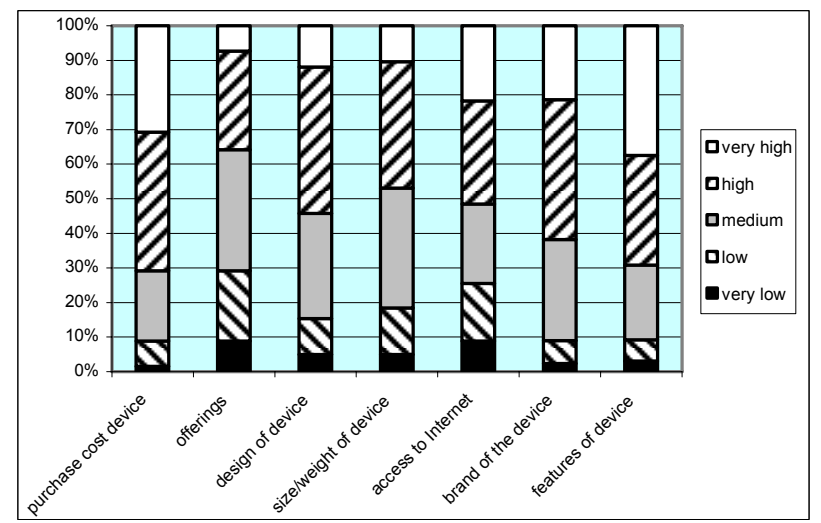

Figure 8: The sample used (preference criteria of a mobile device)

Since our purpose was to find out whether the quality criteria were properly grouped into the eleven subdimensions of m-service quality, we employed confirmatory factor analysis. In the process of factor analysis, it is important to see how much of a quality criterion's variance is shared with all the other quality criteria (variables). It was found that the values of all communalities (estimates of variables' common variance) were indeed high (Table III). As a factor extraction method we selected the principal component analysis (PCA). Noteworthy the choice of the appropriate method was not of primary importance, since in most applications both component analysis and common factor analysis give essentially identical results, in case that the communalities exceed .60 for most variables.

As it is shown in the Component Matrix (Table IV), illustrating the correlations between the variables and the corresponding component (loadings), eleven components were extracted. Upon the application of the scree test criterion, the point at which the plot changes its downward slope indicated that the maximum number of components to extract was eleven. Concluding, it is important to be stressed that the 40 quality criteria were properly grouped into the 11 sub-dimensions of the suggested theoretical framework.

\section{CONCLUSIONS}

This paper presented the core dimensions and subdimensions of m-service quality. The first and most important step to improve quality is the identification of its components. According to our suggestions, the core dimensions of m-service quality are: (i) interaction 
quality, (ii) environment quality, and (iii) outcome quality. Interaction quality comprises the sub-dimensions of expertise, problem solving, information, security/privacy, and customization/personalization. Environment quality can be achieved though the sub-dimensions of equipment, design, and context. Finally, outcome quality consists of the sub-dimensions of reliability, tangibles, and valence. In order to validate the suggested quality model, a survey was conducted among the users of various kinds of $\mathrm{m}$ services (locating points of interest, banking, gaming, etc.). The survey resulted in 260 completed questionnaires. Using confirmatory PCA, eleven principal components were extracted with eigenvalues $>1$ (as exactly the number of sub-dimensions of the suggested model). These components explain 67.5 per cent of the total variance in the $40 \mathrm{~m}$-service quality criteria used in our survey.

By reviewing the literature, we concluded that the model suggested by $\mathrm{Lu}$ et al. in [11] is a contemporary approach, appropriate to define m-service quality. It is based on three core dimensions which were found in many other researchers' work. However, we considered that a few changes need to be made concerning specific subdimensions. In detail, we added in our model the subdimensions of security/privacy and customization/ personalization. As we stressed in Section II, security and privacy issues still have a strong impact on the m-service quality, despite the technological advances in network channels and devices. Communication channel threats are significant network-centric aspects of m-services that need to be considered. Mobile device's instant connectivity and user-friendliness make it an ideal tool for e-crime activities [33]. Besides, malicious users can easily find their unsuspected victims, because security awareness in mobile environment is still in its infancy. We also stressed the importance of customization/personalization upon the delivery of m-service quality. Users prefer to access more personalized and customized services using their mobile devices. The goal of mobile applications should increasingly make their services more personalized and customized towards users. Consequently, personalization and customization should be considered as technologies to enable service differentiation down to the level of the individual [34]. It should also be mentioned, that in our model we omitted the attitude sub-dimension since we believe it should be included in personalized and customized aspects of m-services. Regarding the dimension of outcome quality, we changed the subdimension punctuality to reliability, since the second term has a broader meaning and covers the timely accurate aspects of punctuality.

In our model we did not intentionally examine the impact of the corporate image on the three core dimensions, as illustrated in the model of $\mathrm{Lu}$ et al. Corporate image is an exogenous factor which influences all the components of m-service quality and should be examined separately. Besides, the purpose of our work was to identify the fundamental attributes of m-service quality (the so-called sub-dimensions) and verify if all the quality criteria which comprise m-service quality are properly grouped into these sub-dimensions. As a proposal for further research, it would be interesting to evaluate the relative importance of those sub-dimensions, enabling the m-service providers to prioritize their initiatives and applications.

\section{REFERENCES}

[1] M. Chae, J. Kim, H. Kim and H. Ryu, "Information quality for wireless internet services", Electronic Markets, vol. 12 no. 1, pp. 38-46, 2002.

[2] A. Seth, H.M. Gupta and K. Momaya, "Quality of service parameters in cellular mobile communication", International Journal of Mobile Communications, vol. 5 no. 1, pp. 68-93, 2007.

[3] V.A. Zeithaml, L.L. Berry and A. Parasuraman, "The Behavioral Consequences of Service Quality", Journal of Marketing, vol. 60 no. 2, pp. 31-64, 1996.

[4] A. Aladwani and P. Palvia, "Developing and Validating an Instrument for Measuring User-Perceived Web Quality", Information and Management, vol. 39 no. 6, pp. 467-476, 2002.

[5] S.I. Swaid and R.T. Wigand, "Measuring the quality of e-service: Scale development and initial validation", Journal of Electronic Commerce Research, vol. 10, no. 1, pp. 13-28, 2009.

[6] M. Wolfinbarger and M.C. Gilly, "eTailQ: dimensionalizing, measuring, and predicting etail quality", Journal of Retailing, vol. 79 no. 3, pp. 183-98, 2003.

[7] V.A. Zeithaml, A. Parasuraman and A. Malhotra, "A conceptual framework for understanding e-service quality: implications for future research and managerial practice", working paper, Report No. 00-115, Marketing Science Institute, Cambridge, MA, 2000.

[8] C. Voss, "Rethinking Paradigms of Service: Service in a Virtual Environment", International Journal of Operations \& Production Management, vol. 23 no. 1, pp. 88-104, 2003.

[9] J.E. Francis and L. White, "Value Across Fulfillment-Product Categories of Internet Shopping”, Managing Service Quality, vol. 14 no. 2/3, pp. 226-234, 2004.

[10] J.V. Chen and B.A. Aritejo, "Service quality and customer satisfaction measurement of mobile value-added services: a conceptual review", International Journal of Mobile Communications, vol. 6 no. 2, pp. 165-176, 2008.

[11] Y. Lu, L. Zhang and B. Wang, "A multidimensional and hierarchical model of mobile service quality", Electronic Commerce Research and Applications, vol. 8, pp. 228-240, 2009.

[12] R. Ladhari, "Alternative measures of service quality: a review", Managing Service Quality, vol. 18 no. 1, pp. 65-86, 2008.

[13] E.T. Loiacono, R.T. Watson and D.L. Goodhue, "WebQual: An Instrument for Consumer Evaluation of Web Sites", International Journal of Electronic Commerce, vol. 11 no. 3, pp. 51-87, 2007 (WebQual was introduced in Marketing Educators' Conference: Marketing Theory and Applications, vol. 13 pp. 432-437, 2002).

[14] C. Grönroos, "A service quality model and its marketing implications", European Journal of Marketing, vol. 18 no. 4, pp. 36-44, 1984.

[15] M. Brady and J. Cronin, "Some new thoughts on Conceptualizing perceived service quality: a hierarchical approach", Journal of Marketing, vol. 65, pp. 34-49, 2001.

[16] R. Rust and R.L. Oliver, "Service quality:Insights and managerial implications from the frontier. In: R. Rust and R. L. Oliver (eds), Service Quality: New directions in theory and practice, Sage publications, Thousand Oaks, CA, 1994.

[17] M. Fassnacht and I. Koese, "Quality of electronic sevices: Conceptualizing and testing a hierarchical model", Journal of Service Research, vol. 9 no. 1, pp. 19-37, 2006. 
[18] A. Parasuraman, V.A. Zeithaml, and L.L. Berry, "SERVQUAL: a multiple-item scale for measuring consumer perceptions of service quality", Journal of Retailing, vol. 64 no. 1, pp. 12-40, 1988.

[19] E. Stiakakis and C.K. Georgiadis, "e-Service Quality: Comparing the Provider's and Customer's Perceptions", Managing Service Quality, Emerald, vol. 19 no. 4, pp. 410-430, 2009.

[20] A. Parasuraman, A. Valarie, V.A. Zeithmal and A. Malhotra, "E-SQUAL. A multiple-item scale for assessing electronic service quality", Journal of Service Reasearch, vol. 7 no. 3, pp. 213-233, 2005.

[21] P.A. Vlachos and A.P. Vrechopoulos, "Determinants of behavioural intentions in the mobile internet services market", Journal of Services Marketing, vol. 22 no. 4, pp. 280-291, 2008.

[22] E. Kar, S. Muniafu, and Y. Wang, "Mobile services used in unstable environments: design requirements based on three case studies", Proceedings of the Eighth International Conference on Electronic Commerce, Fredericton, Canada, 2006.

[23] M.-K. Kim, M.-C. Park and D.-H Jeong, "The effects of customer satisfaction and switching barrier on customer loyalty in Korean mobile telecommunication services", Telecommunications Policy, vol. 28, pp. 145-159, 2004.

[24] H. Lim, "M-Loyalty: winning strategies for mobile carriers", Journal of Consumer Marketing, vol. 23 no.4, pp. 208-218, 2006.

[25] A. Seth, K. Momaya and H.M. Gupta, "Managing the customer perceived service quality for cellular mobile telephony: An empirical investigation", VIKALPA, vol. 33 no. 1, pp. 19-34, 2008.

[26] P.A. Vlachos, G. Giaglis, I. Lee and A.P. Vrechopoulos, "Perceived Electronic Service Quality: Some Preliminary Results From a Cross-National Study in Mobile Internet Services", International Journal of Human-Computer Interaction, vol. 27 no. 3, pp. 217-244, 2011.
[27] V.A. Zeithamal, A. Parasuramana and A. Malhotra, "Service quality delivery through web sites: A critical review of extant knowledge", Journal of the Academy of Marketing Science, vol. 30 no. 4, pp. 362-375, 2002.

[28] P.A. Dabholkar, D.I. Thorpe and J.O. Rentz, "A measure of service quality for retail stores: scale development and validation", Journal of the Academy of Marketing Science, vol. 24 no. 1, pp. 316, 1996.

[29] L.M. Caro and J.A.M. Garcia, "Developing a multidimensional and hierarchical service quality for the travel agency industry", Tourism Management, vol. 29, pp. 706-720, 2007.

[30] C.K.Georgiadis and E. Stiakakis, "Key Issues for the Quality Assessment of Mobile Commerce Services", Proceedings of the 4th Balkan Conference in Informatics (BCI 2009), Thessaloniki, Greece, IEEE Computer Society, pp. 148-153, 2009.

[31] C.K. Georgiadis and S.H Stergiopoulou, "Mobile Commerce Application Development: Implementing Personalized Services", Proceedings of the 7th International Conference on Mobile Business 2008 (ICMB 2008), Barcelona, Spain, IEEE Computer Society CPS, pp. 201-210, 2008.

[32] J. Collier and C. Bienstock, "Measuring Service Quality in ERetailing", Journal of Service Research, vol. 8 no. 3, pp. 260-275, 2006.

[33] G. Elliot and N. Phillips, Mobile Commerce and Wireless Computing Systems, Addison Wesley - Pearson Education. Harlow, England, 2004.

[34] C.K. Georgiadis., "Adaptation and Personalization of User Interface and Content", in I.K. Ibrahim (Ed.) Handbook of Research on Mobile Multimeida, Information Science Reference Inc. (IGI Group-Idea), pp. 266-277, 2006.

TABLE III. COMMUNALITIES

\begin{tabular}{|c|c|c|c|c|c|}
\hline Sub-dimension & $\begin{array}{c}\text { Quality criteria } \\
\text { (variables) }\end{array}$ & Extraction & Sub-dimension & $\begin{array}{c}\text { Quality criteria } \\
\text { (variables) }\end{array}$ & Extraction \\
\hline \multirow{4}{*}{ Expertise } & V1 & 0.682 & \multirow{4}{*}{ Equipment } & V21 & 0.752 \\
\hline & V2 & 0.715 & & V22 & 0.693 \\
\hline & V3 & 0.713 & & V23 & 0.636 \\
\hline & V4 & 0.737 & & & \\
\hline \multirow{4}{*}{ Problem solving } & V5 & 0.684 & \multirow{4}{*}{ Design } & V24 & 0.656 \\
\hline & V6 & 0.698 & & V25 & 0.660 \\
\hline & V7 & 0.700 & & V26 & 0.644 \\
\hline & V8 & 0.737 & & V27 & 0.608 \\
\hline \multirow{4}{*}{ Information } & V9 & 0.700 & \multirow{4}{*}{ Context } & V28 & 0.622 \\
\hline & V10 & 0.611 & & V29 & 0.762 \\
\hline & V11 & 0.676 & & V30 & 0.657 \\
\hline & V12 & 0.690 & & & \\
\hline \multirow{4}{*}{$\begin{array}{l}\text { Security / } \\
\text { privacy }\end{array}$} & V13 & 0.572 & \multirow{4}{*}{ Reliability } & V31 & 0.629 \\
\hline & V14 & 0.728 & & V32 & 0.704 \\
\hline & V15 & 0.692 & & V33 & 0.713 \\
\hline & V16 & 0.610 & & & \\
\hline \multirow{8}{*}{$\begin{array}{l}\text { Customization / } \\
\text { personalization }\end{array}$} & V17 & 0.777 & \multirow{4}{*}{ Tangibles } & V34 & 0.659 \\
\hline & V18 & 0.553 & & V35 & 0.738 \\
\hline & V19 & 0.683 & & V36 & 0.645 \\
\hline & V20 & 0.571 & & & \\
\hline & & & \multirow{4}{*}{ Valence } & V37 & 0.695 \\
\hline & & & & V38 & 0.695 \\
\hline & & & & V39 & 0.555 \\
\hline & & & & V40 & 0.687 \\
\hline
\end{tabular}

Extraction Method: Principal Component Analysis 
TABLE IV. COMPONENT MATRIX ${ }^{\mathrm{a}}$

\begin{tabular}{|c|c|c|c|c|c|c|c|c|c|c|c|}
\hline & \multicolumn{11}{|c|}{ Component } \\
\hline & 1 & 2 & 3 & 4 & 5 & 6 & 7 & 8 & 9 & 10 & 11 \\
\hline V1 & 0.608 & 0.055 & 0.019 & 0.212 & 0.056 & 0.005 & -0.010 & 0.057 & -0.150 & -0.069 & 0.153 \\
\hline $\mathrm{V} 2$ & 0.504 & 0.026 & -0.043 & -0.010 & 0.060 & 0.178 & 0.011 & -0.061 & -0.154 & -0.029 & 0.012 \\
\hline V3 & 0.501 & 0.173 & 0.157 & 0.018 & 0.051 & 0.036 & -0.048 & 0.063 & 0.075 & -0.078 & -0.058 \\
\hline V4 & 0.595 & 0.015 & 0.198 & 0.196 & 0.004 & 0.068 & 0.058 & 0.004 & 0.081 & 0.024 & -0.057 \\
\hline V5 & 0.005 & 0.488 & 0.087 & 0.080 & 0.196 & 0.069 & -0.131 & 0.102 & 0.011 & 0.110 & -0.226 \\
\hline V6 & 0.022 & 0.531 & 0.047 & 0.148 & 0.114 & 0.039 & -0.129 & -0.025 & 0.069 & -0.119 & 0.198 \\
\hline V7 & -0.276 & 0.498 & 0.181 & -0.015 & -0.143 & -0.057 & 0.043 & -0.214 & 0.095 & -0.055 & -0.102 \\
\hline $\mathrm{V8}$ & 0.244 & 0.572 & -0.066 & 0.231 & -0.201 & 0.082 & 0.035 & 0.119 & -0.018 & 0.076 & 0.005 \\
\hline V9 & -0.121 & 0.047 & 0.613 & 0.072 & 0.008 & -0.109 & -0.077 & 0.118 & -0.214 & $2.2 \mathrm{E}-05$ & 0.004 \\
\hline V10 & 0.010 & 0.045 & 0.614 & 0.224 & -0.009 & 0.092 & 0.071 & -0.100 & 0.102 & -0.097 & -0.056 \\
\hline V11 & -0.073 & 0.149 & 0.546 & 0.069 & 0.037 & -0.145 & -0.138 & -0.123 & 0.017 & 0.013 & -0.037 \\
\hline V12 & 0.271 & 0.022 & 0.487 & 0.115 & 0.032 & 0.229 & -0.089 & 0.209 & 0.041 & 0.055 & 0.001 \\
\hline V13 & 0.240 & -0.003 & 0.153 & 0.464 & 0.054 & 0.230 & 0.145 & -0.158 & 0.043 & 0.004 & 0.022 \\
\hline V14 & -0.184 & 0.068 & 0.041 & 0.473 & 0.055 & 0.022 & 0.057 & -0.009 & -0.005 & 0.033 & $5.7 \mathrm{E}-05$ \\
\hline V15 & -0.299 & -0.086 & -0.027 & $\mathbf{0 . 5 0 7}$ & -0.070 & 0.091 & 0.216 & 0.033 & -0.135 & -0.176 & -0.144 \\
\hline V16 & -0.370 & -0.216 & 0.130 & 0.456 & 0.202 & 0.059 & 0.010 & 0.029 & 0.009 & 0.053 & 0.034 \\
\hline V17 & 0.021 & 0.133 & 0.150 & 0.068 & 0.460 & 0.008 & 0.091 & -0.091 & -0.022 & 0.205 & 0.003 \\
\hline V18 & 0.082 & 0.097 & 0.064 & 0.027 & 0.499 & 0.211 & -0.003 & -0.023 & -0.036 & $3.4 \mathrm{E}-05$ & 0.086 \\
\hline V19 & & & & & 7 & 64 & -0.060 & & & .099 & -0.063 \\
\hline V20 & 0.099 & 0.225 & -0.028 & 0.001 & $\mathbf{0 . 4 7 7}$ & 0.051 & -0.020 & 0.028 & -0.090 & -0.049 & -0.049 \\
\hline V21 & -0.191 & 0.002 & -0.034 & 0.117 & 0.152 & 0.463 & 0.211 & 0.067 & 0.097 & 0.015 & 0.097 \\
\hline V22 & -0.165 & 0.287 & 0.279 & 0.093 & 0.003 & 0.485 & 0.188 & -0.310 & 0.044 & 0.082 & -0.028 \\
\hline V23 & 0.134 & 0.154 & 0.151 & 0.116 & 0.117 & 0.493 & 0.149 & 0.014 & 0.211 & 0.146 & 0.193 \\
\hline V24 & 0.239 & 0.171 & -0.288 & 0.209 & -0.029 & -0.033 & 0.459 & 0.116 & -0.214 & 0.001 & 0.003 \\
\hline V25 & 0. & 0. & 0.038 & -0.023 & -0.002 & -0.196 & 0.501 & 0.098 & -0.175 & 0.040 & -0.056 \\
\hline V26 & 0.002 & 0.059 & 0.052 & -0.059 & -0.042 & 0.176 & 0.555 & 0.027 & -0.018 & 0.055 & -0.116 \\
\hline V27 & 0.003 & -0.050 & 0.244 & -0.119 & -0.123 & 0.105 & 0.490 & 0.021 & 0.207 & 0.089 & 0.080 \\
\hline V28 & 0.066 & 0.097 & 0.124 & 0.029 & -0.067 & 0.001 & 0.141 & 0.509 & -0.009 & -0.130 & 0.001 \\
\hline V29 & -0.036 & 0.048 & 0.087 & 0.051 & -0.033 & -0.003 & 0.143 & 0.503 & 0.209 & -0.129 & -0.150 \\
\hline V30 & 0.157 & 0.003 & 0.122 & 0.071 & 0.089 & 0.060 & -0.005 & 0.472 & 0.115 & 0.099 & 0.013 \\
\hline V31 & 0.139 & 0.311 & 0.178 & 0.070 & 0.223 & 0.085 & -0.004 & -0.082 & 0.546 & 0.043 & 0.009 \\
\hline V32 & -0.273 & 0.007 & 0.053 & 0.038 & 0.040 & -0.021 & 0.001 & -0.052 & 0.489 & 0.016 & 0.053 \\
\hline V33 & 0.107 & -0.126 & -0.081 & 0.108 & 0.253 & -0.108 & 0.001 & 0.207 & $\mathbf{0 . 5 1 7}$ & 0.101 & -0.117 \\
\hline V34 & 0.152 & 0.256 & -0.129 & -0.167 & 0.088 & 0.107 & -0.212 & 0.001 & -0.217 & 0.524 & -0.099 \\
\hline V35 & 0.151 & -0.252 & 0.026 & -0.139 & 0.043 & 0.028 & 0.077 & -0.006 & -0.092 & 0.460 & 0.173 \\
\hline V36 & -0.244 & 0.130 & -0.060 & 0.009 & -0.067 & 0.161 & -0.017 & -0.171 & 0.055 & 0.475 & 0.201 \\
\hline V37 & 0.036 & -0.081 & 0.118 & 0.008 & 0.177 & 0.162 & 0.065 & 0.119 & 0.052 & 0.109 & 0.533 \\
\hline V38 & 0.239 & 0.301 & 0.013 & 0.142 & 0.014 & 0.139 & 0.001 & 0.240 & -0.003 & -0.029 & 0.476 \\
\hline V39 & 0.041 & 0.202 & 0.075 & 0.155 & 0.131 & -0.053 & -0.100 & 0.033 & -0.194 & 0.224 & 0.448 \\
\hline V40 & -0.011 & 0.188 & 0.034 & -0.028 & 0.109 & -0.092 & -0.119 & -0.188 & 0.109 & 0.199 & 0.441 \\
\hline
\end{tabular}

Extraction Method: Principal Component Analysis

a. 11 components extracted 